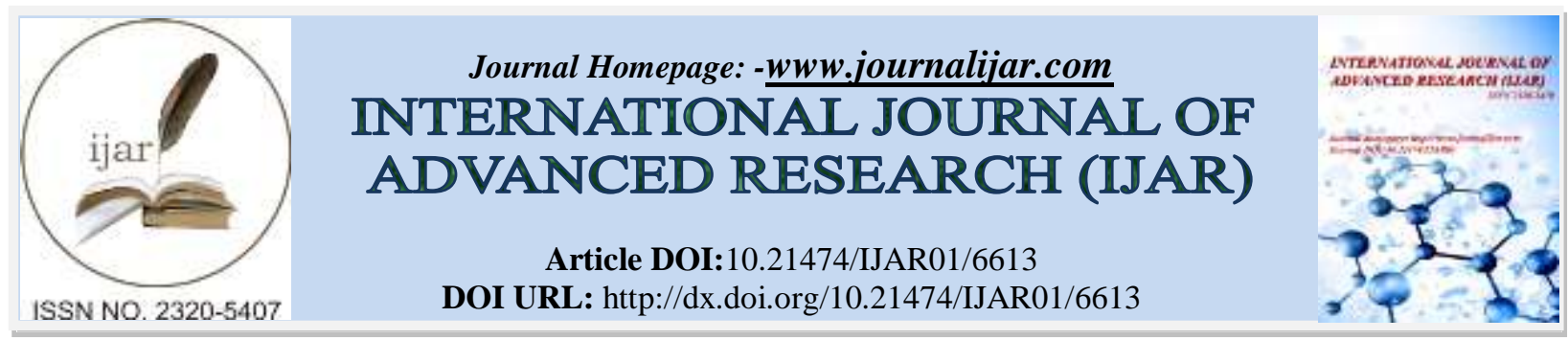

RESEARCH ARTICLE

\title{
URBANIZATION AS A DRIVING FORCE IN SURFACE WATER QUALITY DEGRADATION: THE CASE OF KENYA.
}

\author{
George Ouma Ochola, Daniel Odinde Nyamai and Steve Omari Ngodhe. \\ Rongo University, Department of Environmental studies.
}

\section{Manuscript Info}

Manuscript History

Received: 23 December 2017

Final Accepted: 25 January 2018

Published: February 2018

Keywords:-

Urbanization, surface water quality, driving force, degradation, Kenya.

\begin{abstract}
This study investigates urbanization as a driving force in surface water quality degradation in Kenya. The study is based on the collection of available historical data, supplemented by field observations. Increase in anthropogenic activities which is as a result of urbanization is a major force in changing the hydrological cycle as well as affecting the water quality. Studying the impacts of urbanization on water quality is becoming a wide-focused topic in the region. In this study, the authors attempt to link the urbanization effects such as agricultural development, car wash, industrial effluent management, waste disposal and the subsequent water resources exploitation with the change of water environments in Kenya. Increase in level of industrialization, urbanization, agricultural activities, and population growth have resulted in increased demand for water as well as in an increased flow of contaminants into water bodies. Population increase in urban centres has intensified urban activities which have a direct influence on water quality within hydrographic basins because effluents flow into waterways in many cases without passing through any treatment process. The most significant contamination routes are those related to direct and indirect emissions of treated and untreated sewage, runoff, atmospheric deposition, and pollution. The quality of surface water has become a critical issue in many countries, especially due to concern about the scarcity of water, requiring a program for monitoring the surface and groundwater to protect this resource. In general, the unplanned urban development in Kenya has significantly degraded the region's water resources and significant actions such as upgrading the sewage waste disposal system, locating other sources of water supply, and strict water management will all be needed to resolve the problems that have arisen. The study suggests an adoption of the environmental management slogan which states "Our surrounding, our well-being and our prolonged perfect life."
\end{abstract}

Copy Right, IJAR, 2018,. All rights reserved.

\section{Introduction:-}

Urbanization is a gradual process by which agricultural, business or administrative centres grow into large areas. Growth of urban centre is as a result of population increase as urban draws people from various rural areas in search 
of job opportunities, education, business and other socio-economic openings. Pokhreld and Viraraghavan, 2005 stated that the increasing growth of urbanization due to population pressure and rapid increase in solid waste generation has emerged as one of the main pressing issues of human society, especially in developing countries and according to Markandya, 2006 improper disposal of solid waste leads to contamination of soil, air, and surface and groundwater. This contamination alters physical, chemical, and biological characteristics of the environment and places human health at risk. Urbanization leads to spatial concentration of solid waste, what reduces.

United Nations in the year 2014 reported that globally, more people live in urban areas than in rural areas, with 54 per cent of the world's population residing in urban areas in 2014. In 1950, 30 per cent of the world's population was urban, and by 2050, 66 per cent of the world's population is projected to be urban. In today's increasingly global and interconnected world, over half of the world's population (54 per cent) lives in urban areas although there is still substantial variability in the levels of urbanization across countries (figure 1). The coming decades will bring further profound changes to the size and spatial distribution of the global population. The continuing urbanization and overall growth of the world's population is projected to add 2.5 billion people to the urban population by 2050 , with nearly 90 per cent of the increase concentrated in Asia and Africa. At the same time, the proportion of the world's population living in urban areas is expected to increase, reaching 66 per cent by 2050 (United Nations, 2014).

In the same report it was stated that the planet has gone through a process of rapid urbanization over the past six decades. In 1950, more than two-thirds (70 per cent) of people worldwide lived in rural settlements and less than one-third (30 per cent) in urban settlements. In 2014, 54 per cent of the world's population is urban. The urban population is expected to continue to grow, so that by 2050 , the world will be one-third rural (34 per cent) and twothirds urban (66 per cent), roughly the reverse of the global rural-urban population distribution of the mid-twentieth century.

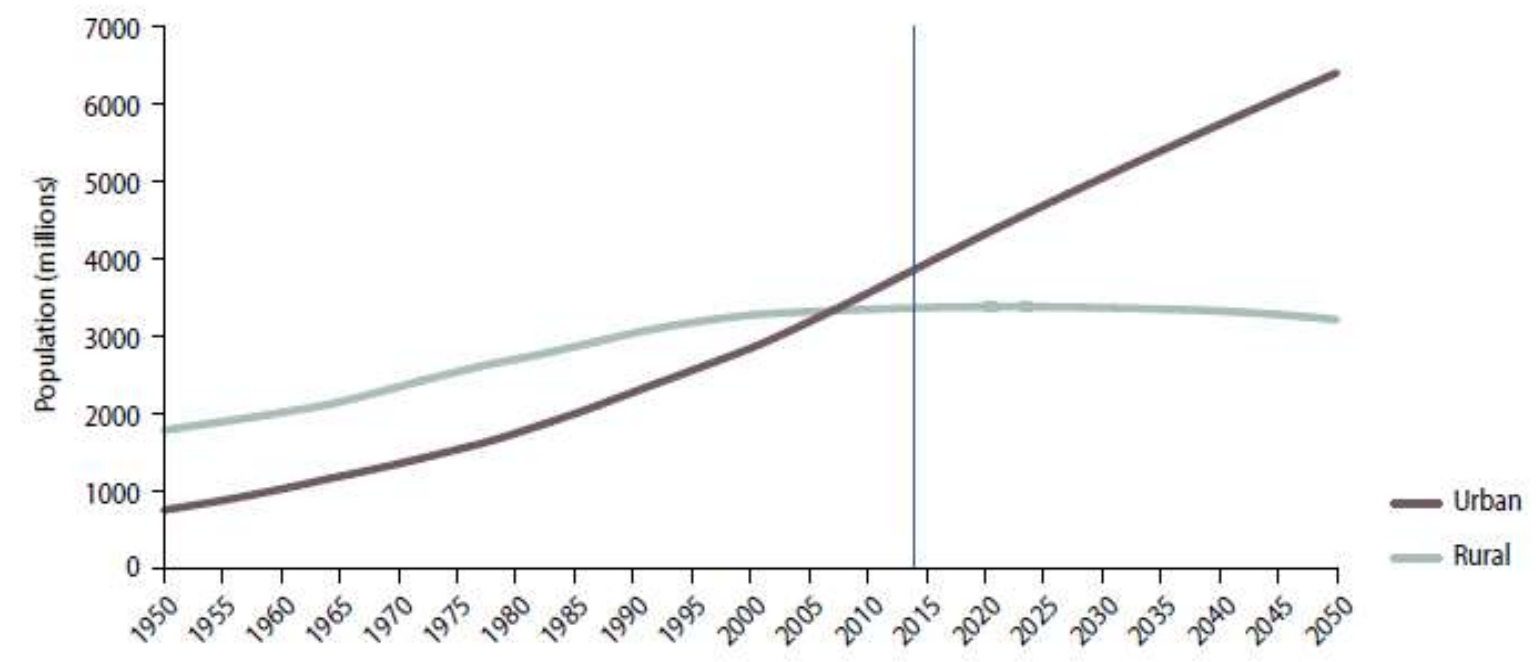

Figure 1:- Urban and rural population of the world, 1950-2050 (Source: United Nations, 2014)

Increase in level of industrialization, urbanization, agricultural activities, and population growth have resulted in increased demand for water as well as in an increased flow of contaminants into water bodies (Pinto, 2009). Population increase in urban centres has intensified urban activities which have a direct influence on water quality within hydrographic basins because effluents flow into waterways in many cases without passing through any treatment process. The most significant contamination routes are those related to direct and indirect emissions of treated and untreated sewage, runoff, atmospheric deposition, and pollution. The quality of surface water has become a critical issue in many countries, especially due to concern about the scarcity of water, requiring a program for monitoring the surface and groundwater to protect this resource (Pesce and Wunderlin 2000). 
Increase in urban population calls for increased demands of urban goods and services. Most of these are provided by nature. Growth of urban centres not only impacts negatively on the environment but also on its resources. Water being one of the most important resources both to human beings and other living organisms face challenges of being degraded in terms of quality, quantity and accessibility. Previous studies have revealed that anything that disrupts water quality, supply and distribution tends to disrupt the very survival of humanity. This study affirms this since no man or any living organism can survive without water. Therefore the important role played by water in various sectors cannot be overemphasized.

Urban population growth (annual \%) in Kenya:-

Increase in annual urban population in Kenya was last measured at 4.31 in 2014; this is according to the World Bank report, 2014. It is calculated using World Bank population estimates and urban ratios from the United Nations world urbanization prospects. This is the latest recorded value, an historical data chart and related indicators for urban population growth (annual \%) in Kenya.

Table 1:- An extract of World Bank Indicators - Kenya -Population density \& Urbanization

\begin{tabular}{|l|l|l|l|l|l|}
\hline & \multicolumn{1}{|c|}{$\mathbf{1 9 9 0}$} & \multicolumn{1}{|c|}{$\mathbf{2 0 0 0}$} & \multicolumn{1}{|c|}{$\mathbf{2 0 1 0}$} & $\mathbf{2 0 1 4}$ & \\
\hline Population density (people per sq. km) in Kenya & 41.2 & 54.9 & 71.2 & 78.8 & {$[+]$} \\
\hline Population in largest city in Kenya & 1380012.0 & 2230079.0 & 3523349.0 & 3767652.0 & {$[+]$} \\
\hline $\begin{array}{l}\text { Population in the largest city (\% of urban } \\
\text { population) in Kenya }\end{array}$ & 32.4 & 36.2 & 39.2 & 32.8 & {$[+]$} \\
\hline $\begin{array}{l}\text { Population in urban agglomerations of more than 1 } \\
\text { million in Kenya }\end{array}$ & 1380012.0 & 2230079.0 & 3523349.0 & 4836060.0 & {$[+]$} \\
\hline $\begin{array}{l}\text { Population in urban agglomerations of more than 1 } \\
\text { million (\% of total population) in Kenya }\end{array}$ & 5.9 & 7.1 & 8.7 & 10.6 & {$[+]$} \\
\hline Urban population growth (annual \%) in Kenya & 4.7 & 3.3 & 4.0 & 4.3 & {$[+]$} \\
\hline Urban population in Kenya & 4264873.3 & 6156979.1 & 8993815.4 & 11304277.0 & {$[+]$} \\
\hline
\end{tabular}

NB: [+]-An increase in population growth over time (Source: World Bank, 2014)

The urban population in Kenya is increasingly growing with no urban planning mechanisms in place, this pose a major threat to water quality. Proper planning and management of water as resource is ideal. The only challenge is that the population grows at a faster rate than what nature can provide. The only alternative left is scrambling and competing for what has been made available by nature. As this takes place, resources not only water are either depleted or degraded. These unplanned urban centres grow haphazardly posing threats to the environment and all its components. Unplanned urban centre has a number of environmental challenges but not limited to: (i) Poor solid and liquid waste management; (ii) rampant land use/land cover changes; (iii) noise, water and air pollution; and (iv) indiscriminate placing of structures which impair free air circulation (World Bank 2014). This study sought to examine urbanization as a driving force to surface water degradation.

Major urban factors contributing to degradation of surface water quality:-

The study identified the following as driving factors leading to degradation of surface water in Kenya.

\section{Urban Solid waste:-}

Marques et al., (2012) asserted that steady growth of urban populations and rapid increase in solid waste generation has emerged as one of the main pressing issues of human society especially in developing countries. As has been mentioned earlier, rapid urban population growth leads to a lot of solid wastes being generated. The study revealed that the management of these solid wastes is still a challenge in most Kenyan urban centres. Nairobi city for instance has a challenge of waste collection and proper disposal despite the effort that has been put by the city council of Nairobi. Some people, especially the ones living along Nairobi River still find themselves dumping their domestic solid wastes into the river directly. This has been a great challenge and threat to water users. The government of Kenya with the help of the National Environment Management Authority had earlier tried to rehabilitate the river but their effort has not achieved much since some of the urban dwellers still dump their waste into the river. The quality of this river water is therefore compromised at the expense of waste management. Athi River is not an exception of the impact that comes from the city of Nairobi and the story remains the same in other water sources in Kenya. 
According to Marques et al., (2012) inappropriate solid waste disposal leads to contamination of soil, air, and surface and groundwater. This alters biological characteristics of the environment including chemical and physical which puts human health at risk. Castilhos Junior, 2006 further postulated that urbanization leads to spatial concentration of solid waste which reduces the potential that environments have to assimilate contaminants. "Environmental contamination resulting from solid waste can reach high levels and negatively affect people and the local fauna and flora." (Castilhos Junior, 2006). Lanza 2009 established that leachate and gases are the major problems caused by garbage decomposition although a series of other problems is also observed such as: a) pollution of soil, nearby surface waters, and ground waters; b) visual pollution; c) unpleasant odors; d) presence of animal scavengers; e) presence of people scavenging discarded resources including children; f) increased occurrence of disease vectors, which directly impact the local and regional human; g) presence of gases with greenhouse and explosive effects, dioxins, and furans resulting from burning; h) intense landscape degradation; i) increase of fire hazard; and j) devaluation of local real estate (Lanza, 2009).

In Migori County (Kenya) for instance, poor solid waste management is also evident. River Migori that passes directly within Migori town is being degraded. A lot of residential structures have been erected along the river and the residents of such places not only wash and bathe directly into the river but also dump waste (plate 1).

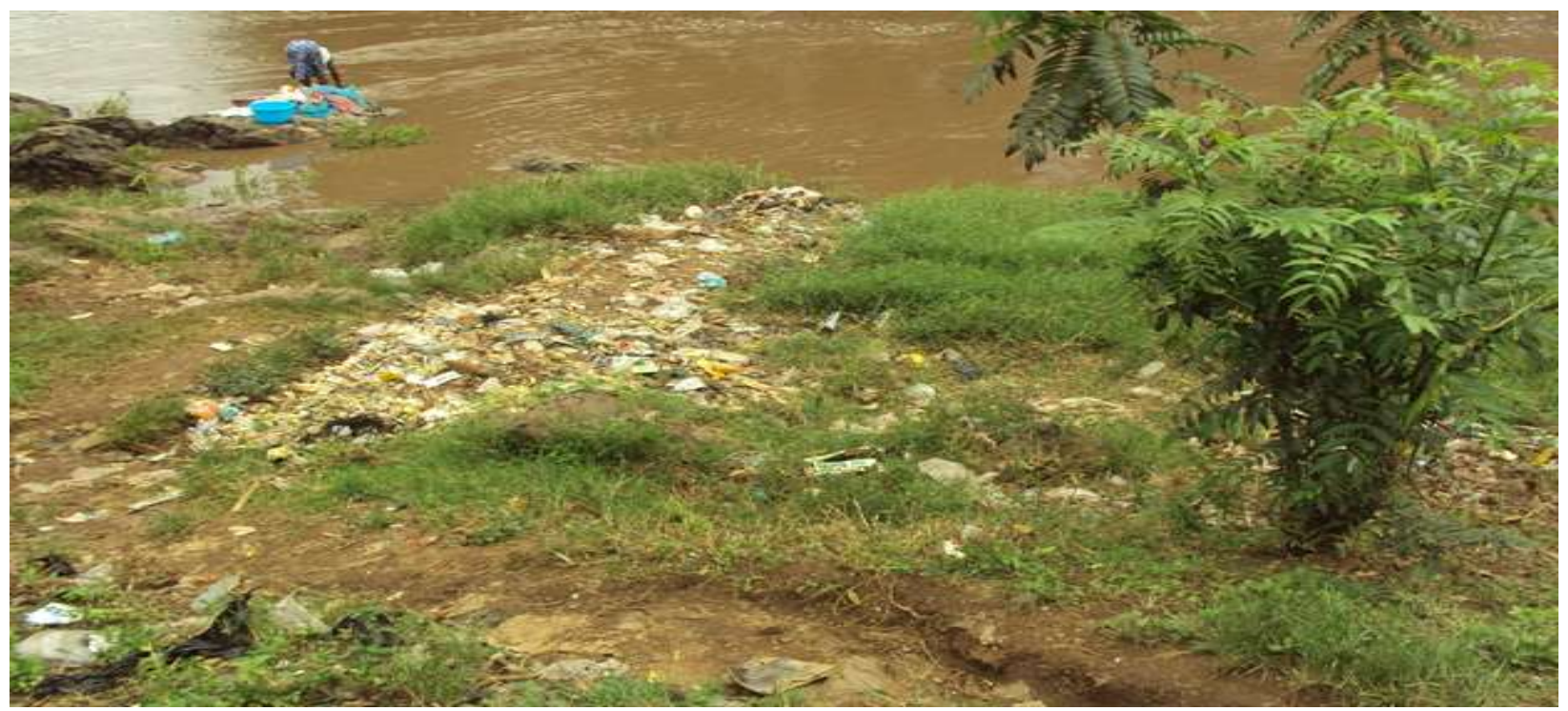

Plate 1:- Direct washing and dumping of waste into the river (Source: Authors)

Excess rainwater generates landfill leachate which percolates the waste layers. Christensen (1989) argued that physical, chemical, and microbial processes transfer pollutants from waste to percolating water. He further established that the effects of leachate on the quality of the surface and ground waters depend on the leachate's composition. Oliveira (2001) affirmed that leachate is by far the most significant threat to groundwater because it can reach the deepest layers of landfills. Zanoni's study of (1972) revealed that through percolation, leachate carries soluble substances and may flow laterally to nearby areas, move upwards and reach the surface or move through the base of the landfill toward the subsurface. This was later proved by Walls (1975). 


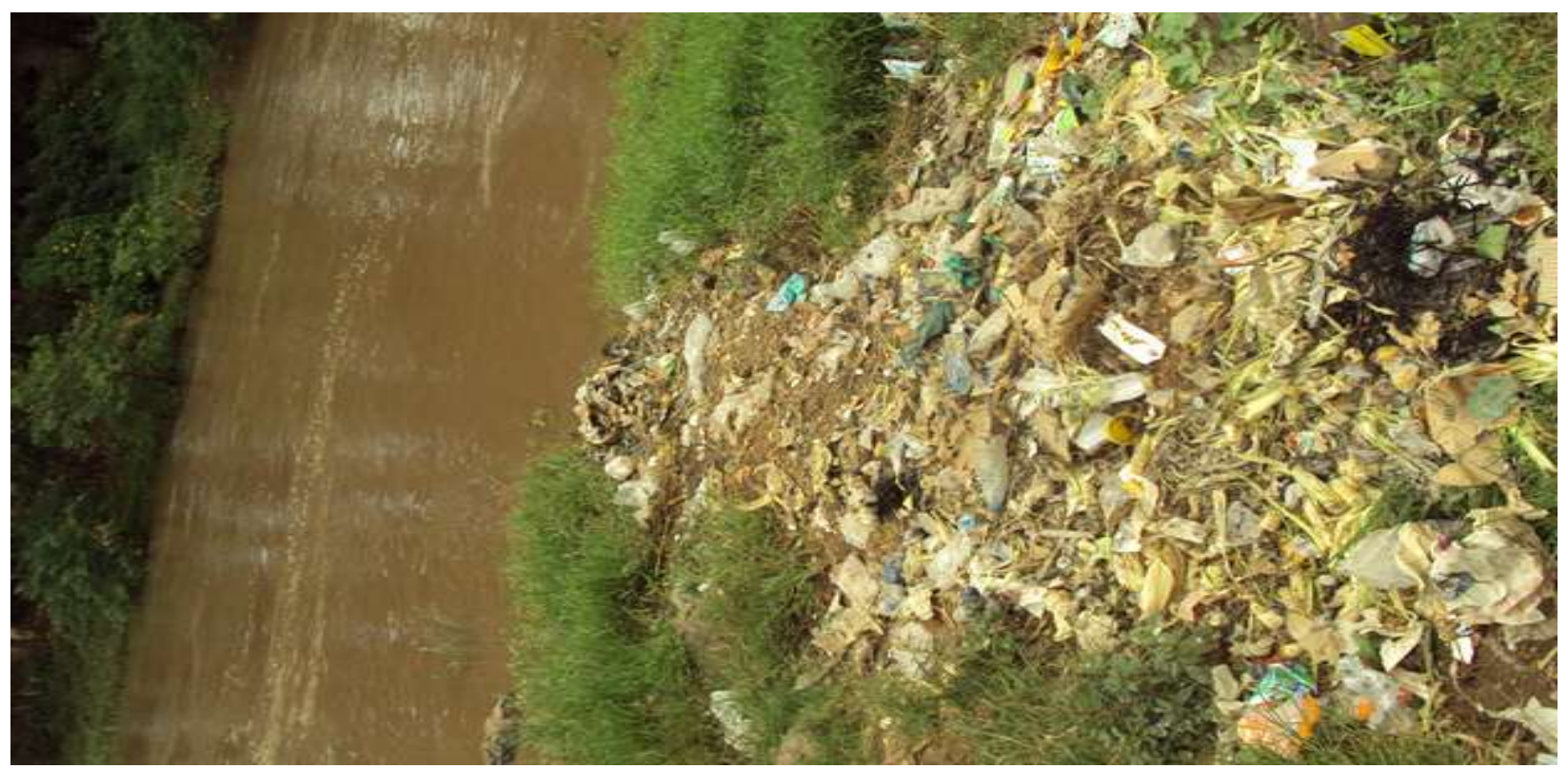

Plate 2:- Solid waste dumped adjacent to River Migori (Source: Authors)

The study established that the public/residents of such urban areas are to blame partially for not having environment at heart. The major problem was found to be irresponsibility of the city or town council in rendering their services of waste collection.

\section{Urban pavement:-}

The built up areas in urban centres not only impact negatively on natural vegetation but also on water resources. The pavement tampers with infiltration rate and hence resulting into a lot of run offs and flooding of relatively flat surfaces. The environmental concern of this is that it affects underground waters as infiltration is reduced. In Kenya, most of the developing urban centres have not channeled proper destination for the run offs. Some of the channels available lead to adjacent rivers or lakes. Existing pipes in some urban areas are also facing maintenance challenges. Some pipes are broken and some are blocked by solid waste. Towns adjacent to water bodies affect the quality of the waters as their run-offs carry things like oil and other chemical substances washed from town.

\section{Urban Agriculture:-}

The study established some of the urban agricultural activities in Kenya where urban dwellers whose residential areas are adjacent to the rivers are taking advantage of planting vegetables at the banks of these rivers and the lake shore. The impacts of these cannot be overemphasized as chemicals used for spraying and fertilizer applied is eventually being washed by run-off into the water bodies. An example of this is evident between Githurai and Kahawa barracks in Nairobi where people grow vegetable along a stream that leads to Nairobi River water degradation. Another example is also evident in Migori town along Migori River together with other numerous examples in Kenya.

\section{Industrial waste/effluent:-}

The Kenyan Environmental Management and Coordination Act of 1999, reviewed in 2015 through NEMA is very clear on effluent management. Waste from industries is supposed to undergo proper treatment before being emptied to a water body such as a river so as not cause harm to the biological resource. A hundred percent treatment has not been achieved in Kenya. The study established that most industries pay little attention on the quality of their treated waste before allowing it into water bodies. Basically most of the industries have a self-sustaining six chambered lagoons for their waste treatment. For instance South Nyanza Sugar Company, the waste in their final chamber/lagoon may appear safe but things such as heavy metals still remain and this leads into the river. Maintenance of waste pipe channels is also a challenge. Some of the waste waters are exposed by the broken pipes. This not only affects the surrounding but also sometimes finds its way into the adjacent water bodies. An example of this is as indicated in the plate 3. 
Industries also emit fumes into the air. Together with the ones that come from vehicles and other machinery used in urban centres, air quality is affected. The study found that in Kenya most of industries have not put in place environmental safety measures like installation of carbon filters in factories. This may at times lead to emission of substances like sulphur dioxide which is a contributing factor to acid rain. These together reach the water bodies direct and even through run off thereby affecting the quality of surface water.

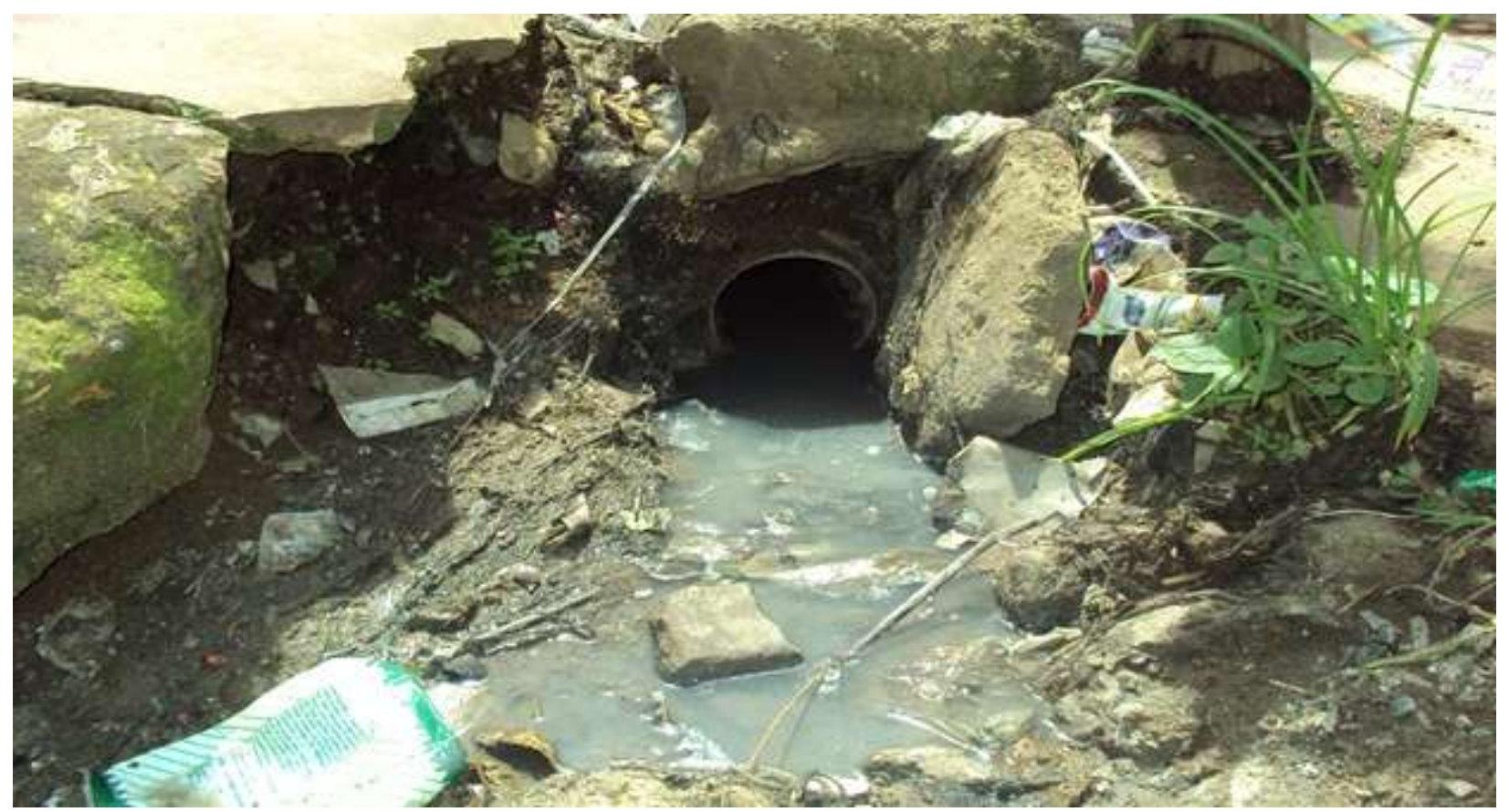

Plate 3:- Open sewer line in Migori town (Source: Authors)

\section{Carwash:-}

Little attention has been given to this issue even though it contributes significantly to water quality degradation. In many urban centres in Kenya, the study found out that majority of the vehicles and motor-bikes are washed directly into streams, rivers, lakes or closely near these water bodies. This activity is undertaken by semi-literate class but the vehicle owners who normally surrender their keys to these job seeking groups sit at a distance as they wait for their vehicles are aware of the environmental impacts that activity has. This means that even the learned and the elites participate in environmental degradation.

The oil from the vehicles or moto-bikes washed into water block free air circulation into the water. It tampers with the respiratory/breathing system of the aquatic organisms and also affects water consumers of such streams, rivers or lakes. This may eventually lead to water related diseases and death of the aquatic organisms.

\section{Conclusion:-}

The study shows that increased population growth in urban centres had led to water quality degradation which results into loss of aesthetic value of the river and other water bodies degraded. The color of water changes and make river to look like sewage. Pollution of these surface waters also has health implications such as respiratory problems and other water related diseases like typhoid, dysentery among others. Besides, these activities cause aquatic ecosystem stress downstream. There is also reduction in economic value of the surface waters degraded.

Proper management of water in Kenyan urban centres is feasible. Despite the benefits that accrue from our urban centres, management of water resource should not be slighted as there is no other resource that it can be substituted with. It is the one and the only one that drives the engine of human and other creatures' body. Its conservation, management and proper utilization is critical. Every individual should have a voice in management since an environmental problem caused by an individual or a group of people not only affect the very people but also impact negatively on the whole community, nation or region. Together let's struggle to give back our waters their life they had before our activities started impacting on them. 
The study suggests an adoption of environmental management slogan for instance which states "Our surrounding, our well-being and our prolonged and perfect life.' Adoption of such slogan brings a sense of reality and practicality in management and utilization of the resources that nature provides for our survival. It calls for individual responsibility in the management of water resource as one of the most importance resource for all living creatures of the world. Collective management of our environmental resources is ideal since the rate at which nature provides is slower than rate of our consumption. Water monitoring technologies are necessary to monitor the quality of the local water.

\section{References:-}

1. Castilho Júnior, A. B (Coord.). Gerenciamento de resíduos sólidos urbanos com ênfase na preservação de corpos d'água: prevenção, geração e tratamento de lixiviados de aterros sanitários. Rkio de Janeiro: ABES, 2006. 494 p.

2. Christensen, T.H.; Kjeldsen, P. Basic biochemical processes in landfills. In: Sanitary Landfilling: Process, Technology and Environimental Impact. Christensen, T.H.; COSSU, R.; Stegmann, R. (eds.). Academic Press, London, UK, p.29, 1989, Cap. 2.1.

3. Holt, M. S. Sources of chemical contaminants and routes into the freshwater environment. Food and Chemical Toxicolgy, Orlando, v.38, p.21-27, Apr. 2000. Supplement 1.

4. Lanza, V. C. V. Caderno Técnico de reabilitação de áreas degradadas por resíduos sólidos urbanos. Belo Horizonte: Fundação Estadual do Meio Ambiente, 2009. 28 p.

5. Markandya A. Water quality issues in developing countries. In: Lopez R, Toman MA, (ed.) Economic Development and Environmental Sustainability. New Policy Options. Oxford University Press, New York, p. 307-344, 2006.

6. Oliveira, S.; Pasqual, A. Avaliação da qualidade da água subterrânea a jusante do depósito de resíduos sólidos municipais de Botucatu/SP. Revista Energia na Agricultura, Botucatu, v.16, n.4, p.25-35, 2001.

7. Pesce, S. F.; Wunderlin, D. A. Use of water quality indices to verify the impact of Córdoba City (Argentina) on Suquia river. Water Research, London, UK, v.34, p.2915-2926, (2000).

8. Pinto, D. B. F. et al. Qualidade da água do Ribeirão Lavrinha na região Alto Rio Grande - MG, Brasil. Ciência e Agrotecnologia, Lavras, v.33, n.4, p.1145-1152, jul/ago. 2009.

9. Pokhrel D.; Viraraghavan T. Municipal solid waste management in Nepal: practices and challenges. Waste Management, New York, v.25, n.5, p.555-562, 2005.

10. Rosângela Francisca de Paula Vitor Marques1, Antônio Marciano da Silva2, Luciano dos Santos Rodrigues3, Gilberto Coelho2 (2012). Impacts of Urban Solid Waste Disposal on the Quality of Surface Water in Three Cities of Minas Gerais - Brazil.

11. United Nations (2014). World Urbanization Prospects. Retrieved from https://www.google.com/?gws_rd=ssl\#q=Urban+and+rural+population+of+the+world $\% 2 \mathrm{C}+1950 \% \mathrm{E} 2 \% 80 \% 93$ $20507^{\text {th }}$ Dec 2016.

12. Walls, J. S. Protecting groundwater from landfill leachate. Water Sewage Works, Hamilton, v.122, p. $68,1975$.

13. World Bank indicators (2014). Kenya-population Density and Urbanization http://www.tradingeconomics.com/kenya/urban-population-growth-annual-percent-wb-data.html retrieved on $7^{\text {th }}$ Dec. 20016

14. Zanoni, A. E. Ground water pollution and sanitary landfills: a critical study. Ground Water, Westerville, v.10, n.3, p.13, 1972 . 